\title{
Sustainable Improvement of Zeolitic Pyroclastic Soils for the Preservation of Historical Sites
}

\author{
Manuela Cecconi ${ }^{1, *(D)}$, Costanza Cambi ${ }^{2}$, Stefano Carrisi ${ }^{3}$, Dimitri Deneele ${ }^{4}$, Enza Vitale ${ }^{5}$ (D) \\ and Giacomo Russo 6 \\ 1 Department of Engineering, University of Perugia, 06125 Perugia, Italy \\ 2 Department of Physics and Geology, University of Perugia, 06123 Perugia, Italy; costanza.cambi@unipg.it \\ 3 Lab. Terra S.n.c, 06055 Papiano (PG), Italy; carrisistefano@libero.it \\ 4 Institut des Matériaux Jean Rouxel (IMN), Université de Nantes, 44322 Nantes, France; \\ dimitri.deneele@cnrs-imn.fr \\ 5 Department of Civil and Mechanical Engineering, University of Cassino and Southern Lazio, \\ 03043 Cassino, Italy; e.vitale@unicas.it \\ 6 Department of Earth Science, Resources and Environment, University of Naples Federico II, \\ 80126 Napoli, Italy; giarusso@unina.it \\ * Correspondence: manuela.cecconi@unipg.it
}

Received: 6 January 2020; Accepted: 26 January 2020; Published: 30 January 2020

\begin{abstract}
Climate changes are inducing a modification of environmental loads on historical sites, requiring new actions towards their conservation. In the paper, the results of an experimental work on sustainable improvement of a pyroclastic soil belonging to the Orvieto cliff (Central Italy) have been investigated in the perspective of its preservation from degradation. The slightly coherent facies of Orvieto Ignimbrite (pozzolana) was treated with hydrated lime and the subsequent chemo-physical evolution was investigated by means of a multi-scale analysis. The beneficial effects obtained from the improvement in terms of mechanical behaviour were interpreted and correlated to the chemo-physical evolution of the system. Microstructural analyses, X-ray diffractometry, thermo-gravimetric analyses (DTG), SEM observations, mercury intrusion porosimetry performed on raw and treated samples, showed that the pozzolanic reactions develop since the very beginning in the system and that the observed mechanical improvement of the treated soil is mainly due to the formation of calcium silicate hydrates (CSH) and calcium aluminate hydrates (CAH). In the paper, the mechanical improvement is put in evidence by comparing the results of oedometer tests performed on both raw and treated samples.
\end{abstract}

Keywords: sustainability; soil improvement; lime treatment; pyroclastic soils; hydro-mechanical behaviour; compressibility

\section{Introduction}

Over the last decades, the geotechnical research has significantly contributed to the preservation of historical sites. It is more recent the awareness that the impact of climate changes is causing an increasingly rapid degradation of the landscape and monumental heritage, requiring new actions towards its conservation, within the integral respect of its material and formal consistency. The geotechnical aspects of heritage conservation require the most advanced methodologies and techniques to be implemented for sustainable mitigation of new challenges introduced by climate changes. In Italy, the case of Orvieto cliff [1] is paradigmatic in this sense. The stability of the cliff is linked to morphological features of the rock mass, but degradation of materials has been increased by the increasing intensity of environmental loads. Wetting and drying cycles of the rock mass surface 
are mainly responsible for its destructuration [2], causing a progressive degradation of the original cementing bonds. For a sustainable and durable conservation, the countermeasures should respect the materic feature of the rock mass and improve its mechanical resistance to face erosion and progressive degradation of the layers most exposed to environmental loads. In this experimental study, the hydro-mechanical improvement of the slightly coherent facies (pozzolana) of Orvieto Ignimbrite induced by addition of hydrated lime has been studied. The subsequent chemo-physical evolution has been investigated by means of a multi-scale analysis.

Recent studies focused on the appropriateness and usefulness of lime treatment of pyroclastic soils [3-6], investigating the function played on the engineering features by different parameters, such as lime per cent by weight, type of binder $\left(\mathrm{CaO}\right.$ or $\left.\mathrm{Ca}(\mathrm{OH})_{2}\right)$, water content and curing time. The mechanical improvement is found to depend on different processes, i.e., short-time cation exchange between dissolved calcium ions and the clay minerals surface and hence, the development of pozzolanic reactions depending on the availability of calcium, aluminium and silicon in the system; it follows a microstructural reorganization derived from a redistribution of charges on clay particles in highly alkaline environment [7,8]. Cambi et al. (2016) [9] evidenced that in the case of volcanic soils with low amount of exchanging minerals, cationic exchange only plays a secondary role. Nevertheless, the contribution of each of the mentioned processes should be evaluated along with the mineralogical composition of the natural soil. Guidobaldi et al. (2017) [10] developed an experimental study aimed at investigating the microstructural modifications due to lime addition on a zeolitic pyroclastic soil (rich in Chabazite) belonging to a deposit of the Orvieto cliff in the Umbrian Region (Central Italy). The study showed the high reactivity of the system exhibited by the quick precipitation of hydrates as tangible products of the pozzolanic reactions and clearly responsible for the improvement of the mechanical response of the material upon shearing, which has been found to depend on confining stress, quantity of lime - percentage as well as curing time. In particular, upon shearing, the behaviour of such treated soil is fragile and dilatant; the soil brittleness increases with larger lime contents and longer curing times. For the investigated curing time intervals, the frictional aliquot of shear strength of the lime treated soil appears to be not influenced by the quantity of added lime and the amount of secondary phases, because of their low degree of crystallization.

Starting from these considerations, the main objective of the present paper is to further investigate the link between the chemo-physical evolution detected at particle level and the macroscopic behaviour of the treated pyroclastic soil through the multi-scale analysis approach. The studied soil, whose samples have been retrieved from the base of an outcrop in Orvieto (TR, Italy), is particularly rich in chabazite, belonging to the mineralogical group of zeolites [11], identified as fundamental promoters of the reaction between $\mathrm{Ca}^{2+}$ ions and pozzolanic soil. Conventional 1D restrained-compression tests (oedometer tests) were performed on reconstituted samples of raw and lime treated soil in order to detect any modifications in the compressibility properties of the material. The modification of compressibility properties has been directly linked to the formation of physical bonding between grains due to precipitation of hydrates after lime addition, as detected by means of different microstructural investigations. As a result, lime treated pyroclastic soil showed an increased yield stress and an improved compressive strength.

\section{Material and Methods}

The investigated material belongs to the Northern part of the Roman Magmatic Province in the Vulsini district (Central Italy), locally known as the Orvieto-Bagnoregio Ignimbrite [12]. A polyphasic eruptive pattern characterized the volcanic activity of the Vulsini District: a first strombolian and effusive activity, followed by caldera-forming eruptions associated with ignimbrite deposits and a final eruptive phase characterized by strombolian magmatic and hydromagmatic events [13]. The average thickness of the ignimbrite deposits in the studied area is about 10 meters, but it reaches a maximum value of 60 meters in the town of Orvieto, sited on the top of a small plateaux resulting from intense erosion processes. These deposits exhibit two facies, a weak rock material (tuff facies) and a slightly 
coherent pozzolana facies. The investigated soil, here denoted as OR soil (identified as PWD4 by Gentili et al. (2014) [11]), belongs to the pozzolana facies (Figure 1) and it is largely enriched in zeolites.

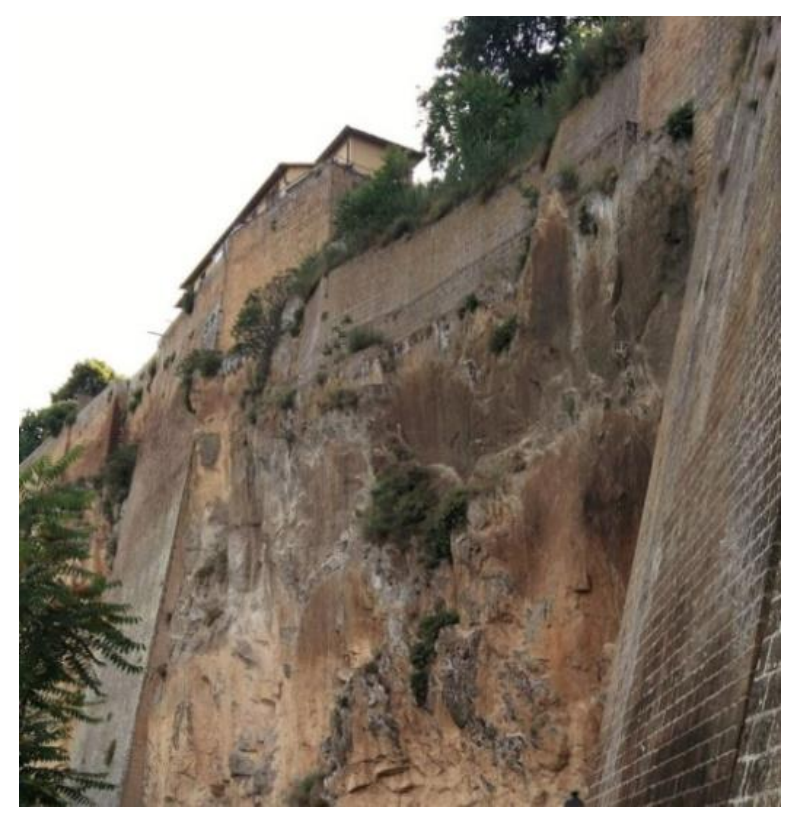

Figure 1. The Orvieto southern cliff. The samples were retrieved at the base of the outcrop.

The raw OR soil was crushed and the fraction passing to the sieve $450 \mu \mathrm{m}$ selected and oven-dried for $24 \mathrm{~h}$ at $60^{\circ} \mathrm{C}$. Mineralogical and chemo-physical properties of OR natural soil (raw material) are described in Guidobaldi et al. (2017) [10]. The OR-soil is characterized by a relevant presence of Ca-chabazite and iron-enriched altered amorphous phase, both clearly identified by SEM observations (Figure 2a,b). The prominent presence of chabazite is furtherly confirmed by all the used investigation techniques. X-Ray powder diffraction also allowed the identification of minor phases such as: sanidine, augite, K-feldspar, analcime and biotite (see Section 3.2, raw material).

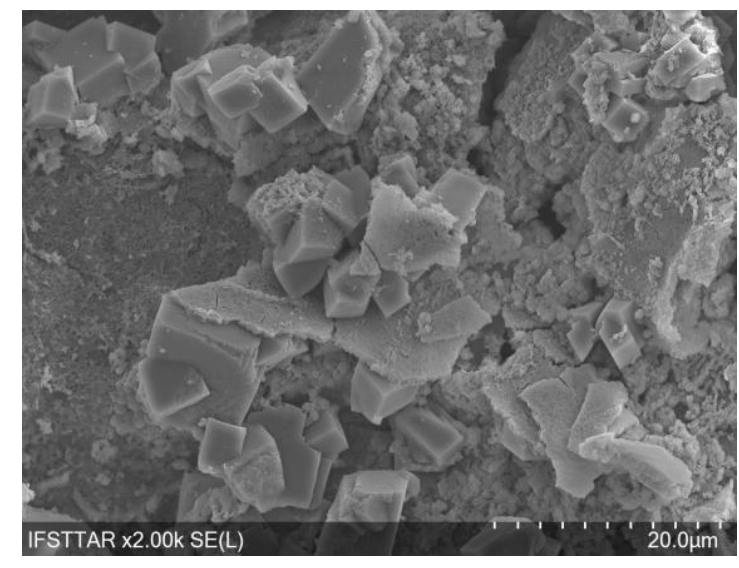

(a)

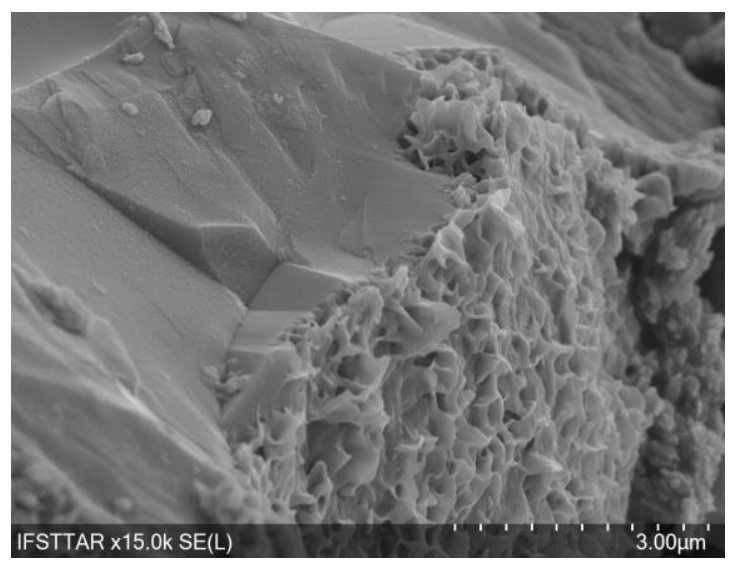

(b)

Figure 2. Micrographs at different magnification factors: (a) Chabazite crystals surrounded by altered amorphous phase, (b) glassy amorphous phase, altered in its external surface.

Samples preparation of lime-treated samples was carried out identically for mechanical, microstructural and chemo-mineralogical tests: the 5\% of lime (by dry weight of soil) was firstly mixed to the soil; then, once obtained a homogenous powder, the $20 \%$ of distilled water (by dry weight of soil) was added to the soil-lime mixture. The hydrated lime used for treatment is composed of more 
than $95 \%$ by Portlandite. Reconstituted samples were compacted in three layers. After compaction, the specimens were stored before testing in order to avoid environmental contamination and drying. Microstructural investigation was carried out for a wide range of curing times, from $24 \mathrm{~h}$ to 90 days, while mechanical testing was performed until 28 days of curing. Several investigation techniques and analyses were performed to gain an insight of the microstructural features of raw and lime treated OR soil.

At the micro-scale of investigation, the experimental programme consisted overall of mineralogical and thermogravimetric analyses (XRD, DTG), as well as scanning electron microscopy analyses (SEM).

XRD analyses were carried out using a Brucker AXS D8 Advance Diffractometer with CuK $\alpha$ $(\lambda=0.154 \mathrm{~nm})$ radiation and a step size of $0.021^{\circ}$ on crushed and randomly oriented powders.

A quantity of 50-100 mg of finely ground material was used for thermogravimetric analyses and heated at a rate of $10{ }^{\circ} \mathrm{C} \mathrm{min}-1$, from lab-room temperature up to $1000^{\circ} \mathrm{C}$. A Netzsch STA 449F3 Jupiter instrument was used, equipped with a mass spectrometer; Netzsch Proteus software was used for results interpretation. Further details are given in Guidobaldi et al. (2017) [10].

Mercury Intrusion Porosimetry (MIP) on the raw and lime treated samples was carried out by means of the Micromeritics AutoPore III, which allows to detect pore diameters from $0.07 \mu \mathrm{m}$ to $300 \mu \mathrm{m}$ (max Hg pressure respectively 0.20685 MPa and 206.85 MPa).

With regard to laboratory geotechnical tests, an oedometer conventional apparatus was adopted. Vertical stress was conventionally applied in subsequent steps $\left(\Delta \sigma_{\mathrm{v}} / \sigma_{\mathrm{v}}=1\right)$. Samples were tested in unsaturated conditions, without performing suction measurements before and during testing. The applied stress levels during loading and unloading stages ranged between $\sigma_{\mathrm{v}}=25 \mathrm{kPa} \div 6400 \mathrm{kPa}$. Vertical displacements were measured by means of micrometer dial gauges with an accuracy of $0.001 \mathrm{~mm}$.

\section{Results and Discussion}

\subsection{Physical Properties of Raw Samples}

OR raw soil presents a partial saturation characterized by $S_{r}=47 \%$ and initial average water content of about $15 \%$. The material used for sample preparation is classified as a silty sand with max. grain dimensions, $D_{\max }=0.425 \mathrm{~mm}$; the grain size distribution is shown in Figure 3. In Table 1, physical properties of OR soil in its natural state and the initial physical properties of the investigated samples are reported.

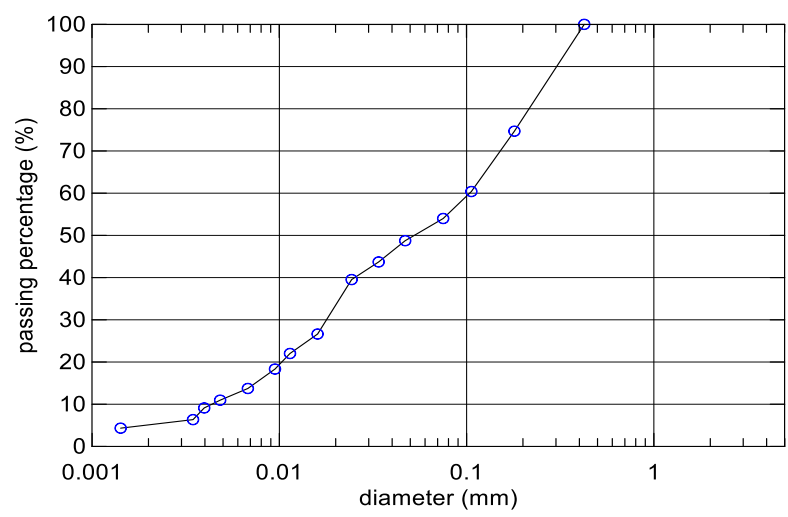

Figure 3. Grain size distribution of the investigated OR raw soil used for lime treatment.

Table 1. Physical properties of natural OR deposit (in situ) and OR laboratory samples.

\begin{tabular}{cccccccccc}
\hline \multicolumn{1}{c}{ In Situ } & \multicolumn{7}{c}{ Laboratory } \\
\hline $\mathbf{w}$ & $\mathbf{G}_{\mathbf{s}}$ & $\mathbf{S}_{\mathbf{r}}$ & $\gamma$ & $\gamma_{\mathbf{d}}$ & $\mathbf{w}$ & $\mathbf{S}_{\mathbf{r}}$ & $\gamma_{\mathbf{d}}$ & $\mathbf{n}$ & $\mathbf{e}$ \\
\hline$(\%)$ & $(-)$ & $(\%)$ & $\left(\mathrm{kN} / \mathrm{m}^{3}\right)$ & $\left(\mathrm{kN} / \mathrm{m}^{3}\right)$ & $(\%)$ & $(\%)$ & $\left(\mathrm{kN} / \mathrm{m}^{3}\right)$ & & \\
\hline 15 & 2.43 & 47 & 15.8 & 13.7 & 22 & 61.0 & 13.0 & 0.47 & 0.88 \\
\hline
\end{tabular}


Finally, during the present study, the hydraulic properties of OR material have been preliminary estimated. It is very well known that several mathematical equations have been proposed in the literature to describe the soil-water retention curve (SWRC), provided that the grain size distribution is known. Arya and Paris (1981) [14] originally proposed such approach in the field of soil physics; the method still seems to be very effective in predicting the SWRC for different soils, including stabilized soils, as well as being very advantageous for its simplicity [15]. In the Arya and Paris model (AP model), the fundamental assumption is that the pore diameter, $d_{\mathrm{i}}$ (pores are assumed as cylindrical capillary tubes) can be related to the mean grain (spherical) diameter $\left(D_{\mathrm{i}},\right)$ for each $i^{\text {th }}$ particle-size class, according to:

$$
d_{i}=D_{i}\left[2 e \frac{n_{i}(1-\alpha)}{3}\right]^{\frac{1}{2}}
$$

and

$$
s_{i}=\frac{4 T_{w}}{d_{i}}
$$

where $n_{i}, e$ and $s_{i}$ represent respectively the number of spherical particles per unit sample mass, the voids ratio and suction (which is related to pore diameter $d_{i}$ ). The quantity $T_{w}$ is the surface tension of water $\left(T_{\mathrm{w}}=7.27 \times 10^{-2} \mathrm{~N} / \mathrm{m}\right.$ at $\left.20^{\circ} \mathrm{C}\right)$, while $\alpha$ is a constant parameter, generally larger than unity (1.38); the value of parameter $\alpha$ is comparable with the one evaluated for other typical pyroclastic weak rocks and coarse-grained soils of Central Italy $[16,17]$. The resulting soil water retention curve is reported in Figure 4.

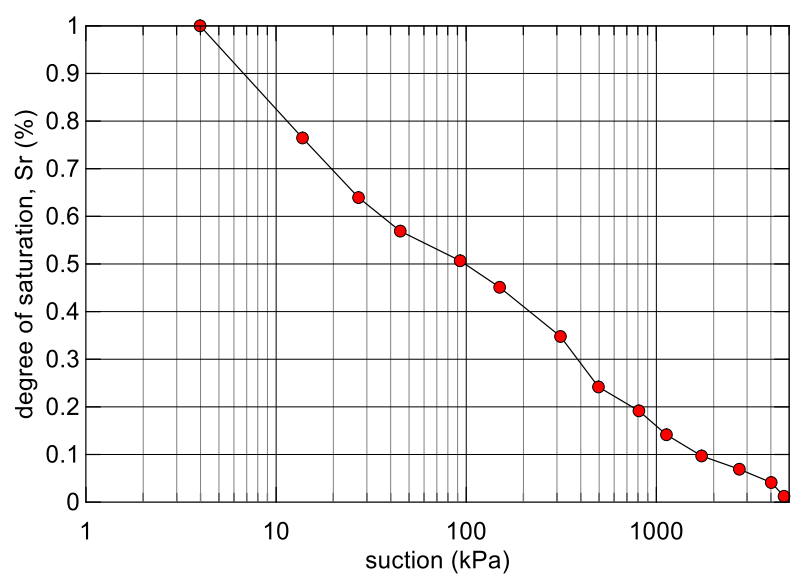

Figure 4. Soil water retention curve of OR raw material (SWRC).

\subsection{Chemo-physical Characterization of Lime-Treated Samples}

The X-ray diffraction patterns of OR soil treated with $5 \%$ by weight of $\mathrm{Ca}(\mathrm{OH})_{2}$ is shown in Figure 5. The mineralogical evolution of the system was monitored over time, from $24 \mathrm{~h}$ to 90 days of curing. The main phases added through lime are portlandite and a small fraction of calcite. Calcite is steadily detected until 90 days of curing, meaning that it is not involved in the ongoing reactions. Portlandite actively promotes and participates to the reactions taking place in the system and it is quickly consumed. Signals ascribable to portlandite are never detected, thus suggesting that it is entirely consumed within $24 \mathrm{~h}$ after the addition. 


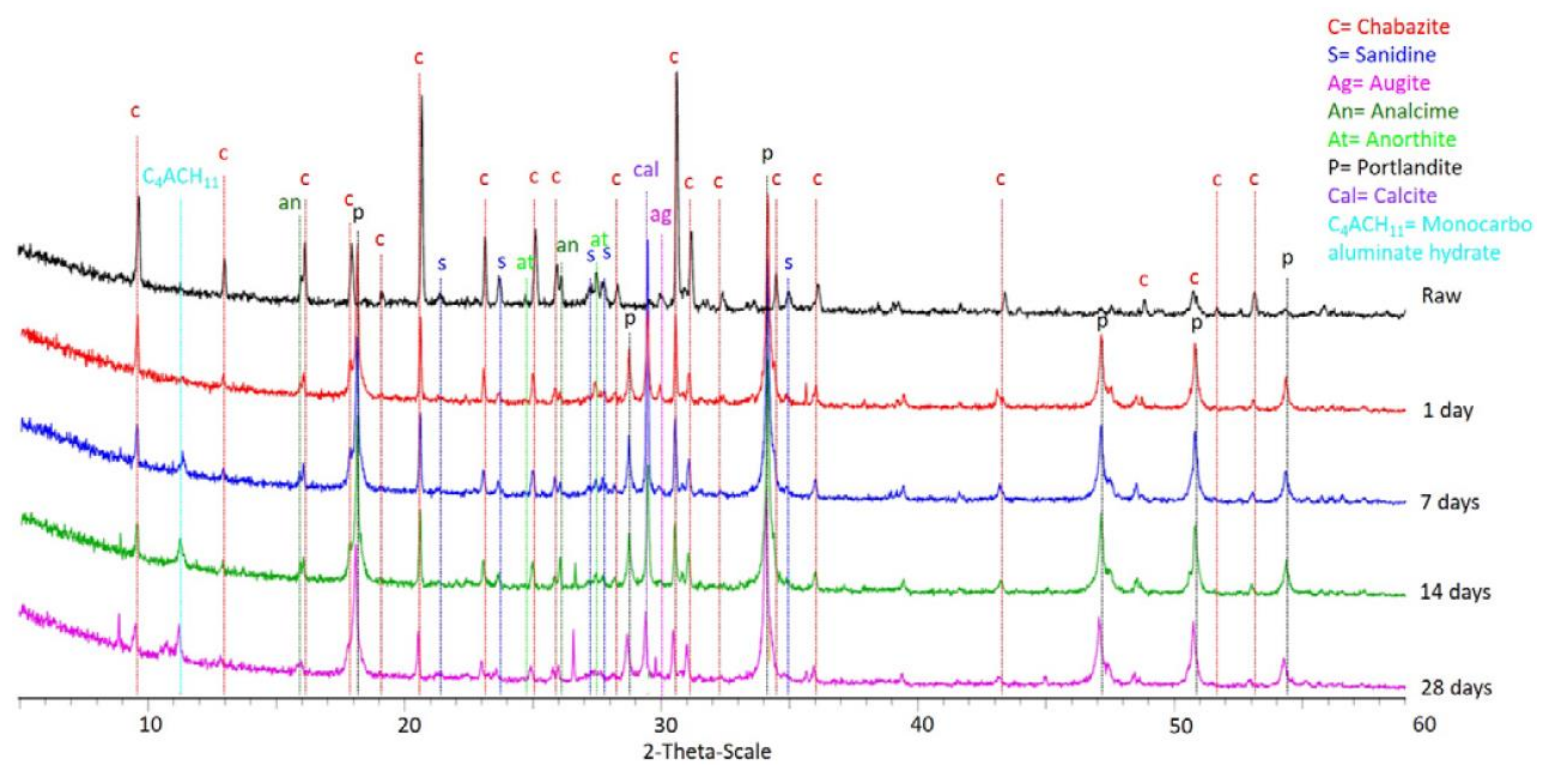

Figure 5. X-ray diffractograms obtained for raw and lime treated OR soil at increasing curing time (from Guidobaldi et al. (2017) [10]).

Figure 6 shows the DTG curves of raw and lime treated OR samples at increasing curing times. Orvieto DTG natural curve is mainly affected by Chabazite-Ca. The characteristic double peak of dehydration of Chabazite (between $50^{\circ} \mathrm{C}$ and $250{ }^{\circ} \mathrm{C}$ ) plausibly indicates the presence of molecular water absorbed in two different sites [18]. Immediately after lime addition, the two peaks of chabazite quickly smoothen. The main peak of portlandite dehydroxilation at around $450^{\circ}$, is just slightly visible after 1 day of curing. It completely vanishes for longer curing times. The signal of decarbonation $\mathrm{CaCO}_{3} \rightarrow \mathrm{CaO}+\mathrm{CO}_{2}[19]$ decreases in time as well. After 90 days, there is still no sign of hydrates formation for temperature ranging around $300^{\circ} \mathrm{C}$, typical of C-S-H. Nevertheless, it is clearly detectable in the interval 1-90 days a constant increase of the $\%$ mass loss around $100{ }^{\circ} \mathrm{C}$.

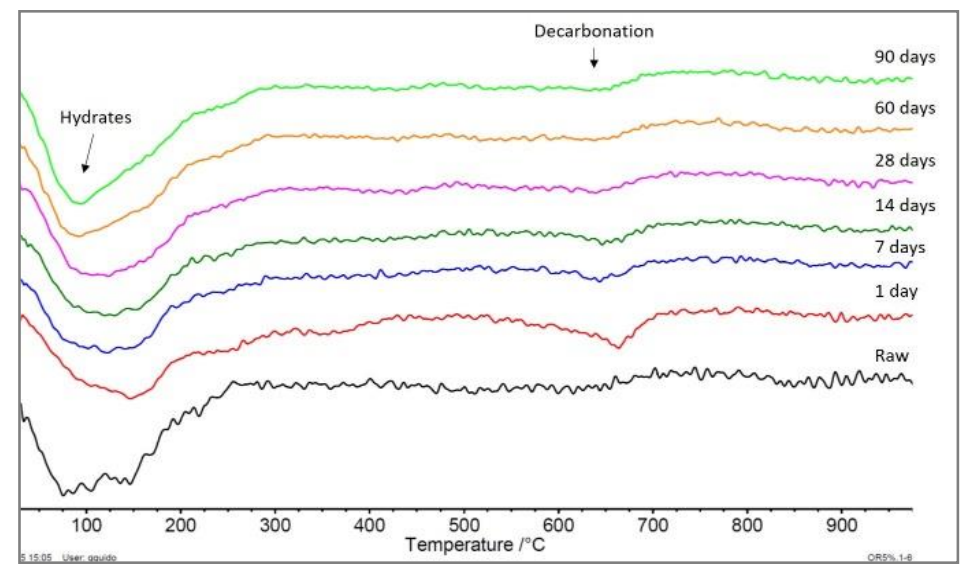

Figure 6. OR-soil: results of thermogravimetric analyses (DTG) on 5\% lime treated samples for different increasing curing times (from Guidobaldi et al. (2017) [10]).

MIP of raw OR soil samples allowed the identification of three main classes of pores (Figure 7). The first two classes are mainly composed of inter-particles voids while the main contribution to the smaller pore population is mainly given by the intrinsic porosity of the altered iron-enriched amorphous phase. Differently from soils formed by exchanging clay minerals, no microstructural reorganization is detected after the addition of lime. Treated samples show a bimodal distribution, with similar modal sizes. In the smallest pore range (entrance diameter $<0.1 \mu \mathrm{m}$ ) an increase of frequency is observed in 
the very short term ( $24 \mathrm{~h}$ of curing), indicating the formation of a new pore class due to precipitation of secondary hydrates phases in form of gel. Increasing the curing time, a progressive filling of cavities and voids is due to the precipitation of secondary phases, with the progressive decrease of frequency of each class, even if the modal size of the two main classes of pores is not relevantly changed. This observation is evident for $0.3-3 \mu \mathrm{m}$ pore entrance diameters within the first 28 days of curing. The filling is less relevant for $3-12 \mu \mathrm{m}$ pore entrance diameters. The precipitation of hydrates is congruent with the formation of the smallest class of pores, particularly evident after 28 days of curing.

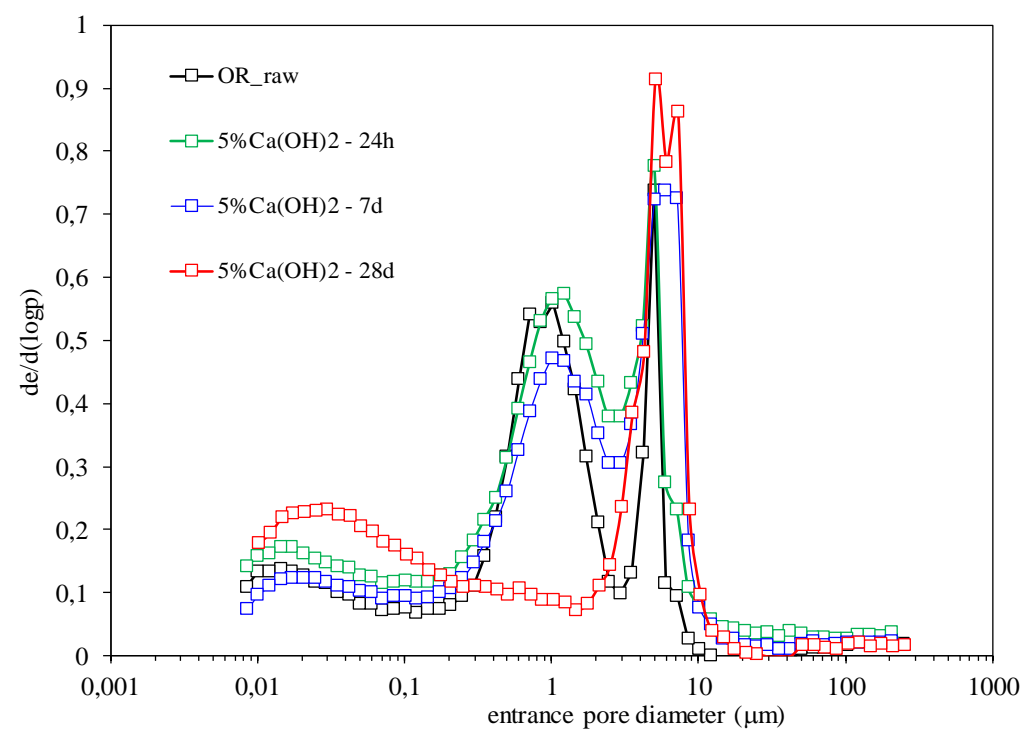

Figure 7. Pore size distribution evolution for raw and lime treated OR soil at increasing curing time (adapted from Guidobaldi et al. (2018) [20]).

\subsection{Lime Treatment Effects on the Soil Compressibility}

For a quantitative assessment of the mechanical improvement induced by lime addition, some results of 1D-oedometer tests are herein presented and discussed in terms of compressibility properties; the obtained results (axial strain $\varepsilon_{\mathrm{V}}$ vs. vertical stress, $\sigma_{\mathrm{v}}$ ) are reported in Figure 8. The initial state of raw samples is characterized by voids ratio in the range $\mathrm{e}_{0}=0.86 \div 0.88$, similar to the other values estimated for pyroclastic soils from Central Italy [21]. The initial response of intact samples of this material on first loading $(<100 \mathrm{kPa})$ is moderately stiff. Large volumetric strains occur for vertical stresses higher than about $200 \mathrm{kPa}$. Nevertheless, the maximum stress level upon loading is low from reaching a single normal compression line. First loading induces a gradual transition (yielding) between reversible to irreversible behaviour of the sample with the increase of vertical stresses, with relevant volume changes even before major yield. The influence of curing time is very clear. As already observed for other pyroclastic soils [3], the effect is mainly due to the development of stable bonds between aggregates deriving from the products of pozzolanic reactions. The increase of one dimensional stiffness becomes relevant longer curing times (at least 7 days), but a certain improvement is observed also for treated samples cured for short time ( $24 \mathrm{~h}$ after compaction).

Therefore, lime addition undoubtedly leads to an improvement in the mechanical response within the first month, by reducing the compressibility and increasing the yield stress. This mechanical response can be then interpreted based on the results obtained from the investigation at the microstructural level. In fact, the microstructural analyses of the treated pyroclastic soil showed the high reactivity of the system to lime addition and the rapid development of pozzolanic reactions. 


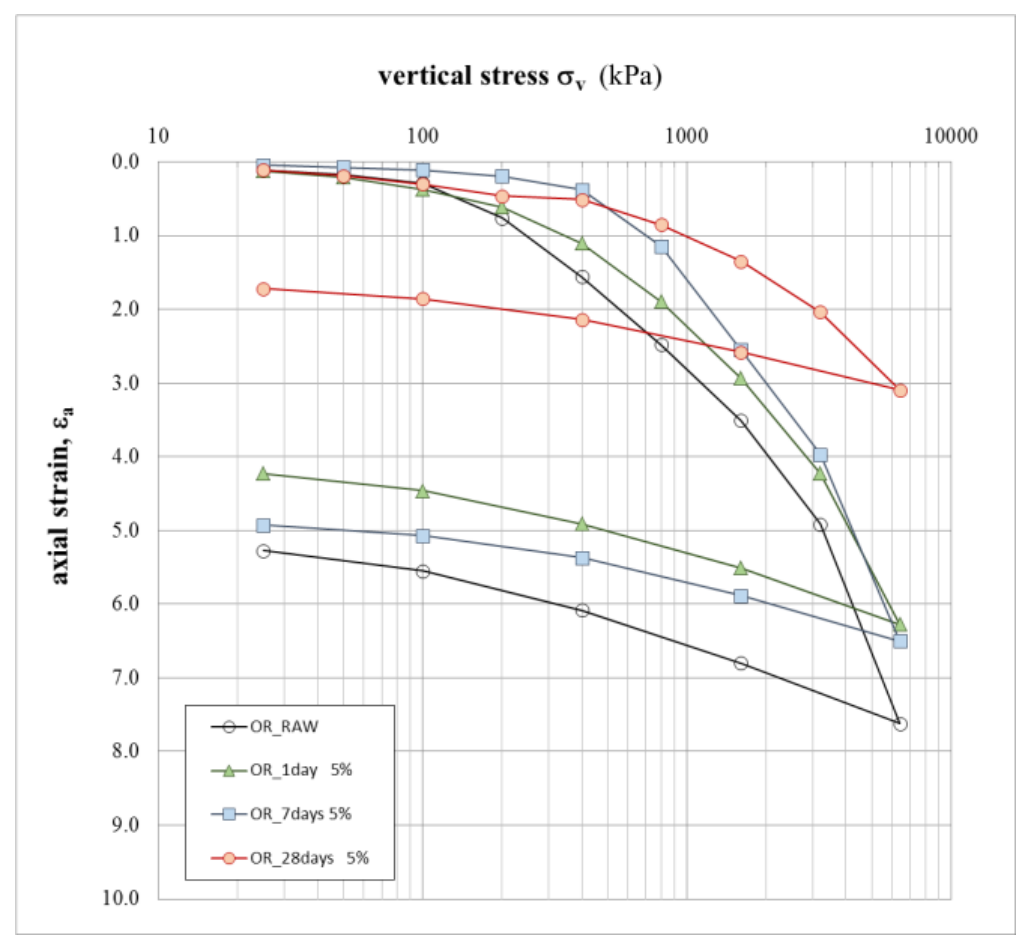

Figure 8. Compressibility curves from conventional oedometer tests on raw and lime-treated OR samples at increasing curing time.

\section{Conclusions}

In the paper, the results of an extensive experimental work on sustainable improvement of a pyroclastic soil belonging to the Orvieto cliff (Central Italy) have been investigated in the perspective of its preservation from degradation. The suitability of Orvieto pyroclastic soil to lime treatment has been analysed by means of a multi-scale analysis. The link between chemo-physical evolution of the soil-lime-water system (microscale level) and mechanical behaviour of treated samples (macroscale level) has been thoroughly investigated. The main findings allow the following conclusions to be drawn, at different scales of investigation:

- portlandite, chabazite and amorphous phases are the main phases involved in pozzolanic reactions induced by lime addition;

- by comparing diffractometer and thermogravimetric analyses, it is evident that secondary hydrated phases, mainly C-A-H and C-S-H, are formed since the very short time;

- the observed compressibility upon loading in oedometer conditions is relevantly affected by the formation of hydrated secondary phases; the reduction of compressibility and the increase of yield stress are directly linked to the amount of newly formed hydrated phases, in turn depending on the amount of added lime and duration of curing time.

Author Contributions: Methodology, M.C., C.C., D.D., G.R.; experimental tests, S.C., E.V.; SEM analyses and interpretation, D.D.; data interpretation, M.C., C.C. and G.R.; writing-review and editing, M.C., G.R. All authors have read and agreed to the published version of the manuscript.

Funding: Part of this research was developed in the context of the Italian project "Ricerca di Base, Esercizio 2018, University of Perugia, titled" Rischio sismico di edifici storici/monumentali: rilievo e monitoraggio, aspetti strutturali e geotecnici ed interventi di ricostruzione post-sisma secondo una progettazione sostenibile" and "Ricerca di Base, Esercizio 2017, University of Perugia, titled "Multi-scale analysis for the correlation of mechanical, micro-structural and chemo -mineralogical evolution of different lime treated soils".

Conflicts of Interest: The authors declare no conflict of interest. 


\section{References}

1. Cencetti, C.; Conversini, P.; Tacconi, P. The Rock of Orvieto (Umbria, Central Italy). G. Geol. Appl. 2005, 1, 103-112.

2. Huang, S.; Wang, J.; Qiu, Z.; Kang, K. Effects of cyclic wetting-drying conditions on elastic modulus and compressive strength of sandstone and mudstone. Processes 2018, 6, 234. [CrossRef]

3. Cecconi, M.; Pane, V.; Marmottini, F.; Russo, G.; Croce, P.; dal Vecchio, S. Lime stabilisation of pyroclastic soils. In Proceedings of the 5th International Conference on Unsaturated Soils, Barcelona, Spain, 6-8 September 2010; Volume 1, pp. 537-541.

4. Cecconi, M.; Russo, G. Microstructural features of lime-stabilised pyroclastic soils. Géotechnique Lett. 2013, 3, 124-129. [CrossRef]

5. Avsar, E.; Ulusay, R.; Aydan, Ö.; Mutluturk, M. On the difficulties of geotechnical sampling and practical estimates of the strength of a weakly bonded volcanic soil. Bull. Eng. Geol. Environ. 2015, 74, 1375-1394. [CrossRef]

6. Russo, G.; Vitale, E.; Cecconi, M.; Pane, V.; Deneele, D.; Cambi, C.; Guidobaldi, G. Microstructure insights in mechanical improvement of a lime-stabilised pyroclastic soil. Volcanic Rocks and Soils. In Proceedings of the International Workshop on Volcanic Rocks and Soils, Ischia Island, Italy, 24-25 September 2015; pp. $289-294$.

7. Chemeda, Y.C.; Deneele, D.; Christidis, G.E.; Ouvrard, G. Influence of hydrated lime on the surface properties and interaction of kaolinite particles. Appl. Clay Sci. 2015, 107, 1-13. [CrossRef]

8. Vitale, E.; Deneele, D.; Russo, G.; Ouvrard, G. Short term effects on physical properties of lime treated kaolin. Appl. Clay Sci. 2016, 132, 223-231. [CrossRef]

9. Cambi, C.; Guidobaldi, G.; Cecconi, M.; Comodi, P.; Russo, G. On the ICL test in soil stabilization. In Proceedings of the 1st IMEKO TC4 International Workshop on Metrology for Geotechnics, Benevento, Italy, 17-18 March 2016; pp. 31-34.

10. Guidobaldi, G.; Cambi, C.; Cecconi, M.; Deneele, D.; Paris, M.; Russo, G.; Vitale, E. Multi-scale analysis of the mechanical improvement induced by lime addition on a pyroclastic soil. Eng. Geol. 2017, 221, 193-201. [CrossRef]

11. Gentili, S.; Comodi, P.; Nazzareni, S.; Zucchini, A. The Orvieto-Bagnoregio Ignimbrite: Pyroxene crystalchemistry and bulk phase composition of pyroclastic deposits, a tool to identify syn- and post-depositional processes. Eur. J. Mineral. 2014, 26, 743-756. [CrossRef]

12. Cappelletti, P.; Langella, A.; Colella, A.; De Gennaro, R. Mineralogical and technical features of zeolites deposits from northern Latium volcanic district. Per. Mineral. 1999, 68, 127-144.

13. Nappi, G.; Antonelli, F.; Coltorti, M.; Milani, L.; Renzulli, A.; Siena, F. Volcanological and petrological evolution of the Eastern Vulsini District, Central Italy. J. Volcanol. Geotherm. Res. 1998, 87, 211-232. [CrossRef]

14. Arya, L.M.; Paris, J.F. A physicoempirical model to predict the soil moisture characteristic from particle size. Soil Sci. Soc. Am. J. 1981, 45, 1023-1030. [CrossRef]

15. Cecconi, M.; Russo, G. Prediction of soil-water retention properties of a lime stabilised compacted silt unsaturated soils: Advances in geo-engineering. In Proceedings of the 1st European Conference on Unsaturated Soils, E-UNSAT, Durham, UK, 2-4 July 2008; pp. 271-276.

16. Cecconi, M.; Pane, V.; Vecchietti, S. Some remarks on physicoempirical models for the prediction of the soil water retention curve. In Proceedings of the Advanced Experimental Unsaturated Soil Mechanics, EXPERUS, Trento, Italy, 27-29 June 2005; Alessandro Tarantino, E., Romero, Y.J., Cui, Eds.; Volume 1, pp. 337-343.

17. Cecconi, M.; Vecchietti, A.; Pane, V.; Russo, G.; Cencetti, C. Geotechnical Aspects in the Assessment of Stability Conditions of the Volumni Hypogeum in Perugia. In Geotechnical Research for Land Protection and Development, CNRIG 2019; Lecture Notes in Civil Engineering; Calvetti, F., Cotecchia, F., Galli, A., Jommi, C., Eds.; Springer: Cham, Switzerland, 2020; Volume 40.

18. Stakebake, J.L. Characterization of natural chabazite and 5A synthetic zeolites. Part I. Thermal and outgassing properties. J. Colloid Interface Sci. 1984, 99, 41-49. [CrossRef]

19. Alarcon-Ruiz, L.; Platret, G.; Massieu, E.; Ehrlacher, A. The use of thermal analysis in assessing the effect of temperature on a cement paste. Cem. Concr. Res. 2005, 35, 609-613. [CrossRef] 
20. Guidobaldi, G.; Cambi, C.; Cecconi, M.; Comodi, P.; Deneele, D.; Paris, M.; Russo, G.; Vitale, E.; Zucchini, A. Chemo-mineralogical evolution and microstructural modifications of a lime treated pyroclastic soil. Eng. Geol. 2018, 245, 333-343. [CrossRef]

21. Cecconi, M.; Rotonda, T.; Verrucci, L.; Tommasi, P.; Viggiani, G. Microstructural features and strength properties of weak pyroclastic rocks from Central Italy, Volcanic Rocks and Soils. In Proceedings of the International Workshop on Volcanic Rocks and Soils, Ischia Island, Italy, 24-25 September 2015; pp. 107-108. 